\title{
Effect of Letrozole on Hyaluronic Acid Concentration of the Endometrial Wash
}

Received: 31-Jul-2020 Accepted: 21-Aug-2020 Published: 14-Dec-2020

\section{Sarab Khalaf Hammood AlJuboory ${ }^{1,2}$, Mufeda Ali Jwad ${ }^{1}$, Nadia Al-Hilli ${ }^{3}$}

${ }^{1}$ High Institute of Infertility Diagnosis and Assisted Reproductive Technologies, Al Nahrain University, Baghdad, Iraq. wsarabw@gmail.com

${ }^{2}$ Ministry of Health, Health Directorate, Kirkuk, Iraq.

${ }^{3}$ Department of Obstetrics \& Gynecology, College of Medicine, University of Babylon, Babylon, Iraq.

Hyaluronic acid (HA) is an anionic, non-sulfated glycosaminoglycan distributed widely throughout connective, epithelial, and neural tissues. The study included 40 infertile females. A full history taking, complete general examination, complete gynecological examination, and infertility workup including basal hormonal analysis, and uterine cavity assessment by ultrasound and tubal patency evaluation by hysterosalpingogram was done in addition to husband's seminal fluid analysis. The control group did not receive any ovarian stimulation drugs, while the $2^{\text {nd }}$ group was treated with letrozole + gonadotropin. The ovarian stimulation protocol was chosen for each patient according to her age, history, and hormonal assay. Evaluation of thickness and pattern of the endometrium, size, and the number of mature follicles was performed by transvaginal ultrasonography on the $2^{\text {nd }}$ day of the menstrual cycle and cycle day 11-14 before hCG injection. The study showed no correlation between HA and LH at triggering day in women who received letrozole plus Gonadotropin but a positive correlation was documented between HA concentration and $\mathrm{E}_{2}$ in addition to a positive correlation with progesterone, the number of follicles, and endometrial thickness at the day of triggering of ovulation. The study revealed that mean hyaluronic acid concentration was elevated significantly $(\mathrm{P}<0.05)$ in pregnant women after stimulation protocol compared with nonpregnant (164.2 vs. $152.1 \mathrm{pg} / \mathrm{ml}$ ). HA was significantly higher in women who undergo ovarian stimulation with letrozole which was a good protocol in the treatment of women with ovulatory problems.

Keywords: Hyaluronic acid; Female infertility; Letrozole; FSH; Gonadotropin. 


\section{Introduction}

Infertility is a disease of the reproductive system, which is defined as the failure to achieve pregnancy after at least one year of regular unprotected sexual intercourse in women $<35$ years who are not using contraception and after six months in women > 35 years or due to an impairment of a person's capacity to reproduce, either as an individual or with his/her partner, it affects about 10-15\% of couples (Bergqvist, et al [1], Campbell, $S^{[2]}$ ). According to the World Health Organization (WHO) definition, a couple is considered infertile if, after 2 years of regular sexual intercourse, without contraception, the woman has not become pregnant (Chun, et al ${ }^{(3)}$ ). Hyaluronic acid (HA) is an anionic, nonsulfated glycosaminoglycan that has a significant role in establishing the cellular microenvironment conducive to the development of the proliferative process. The lack of hyaluronic acid synthase regulation genes causes abnormal production of $\mathrm{HA}$ and promotion of abnormal biological processes such as metastasis and pregnancy loss (AlHussaini and Shaaban ${ }^{[4]}$ ). An increasing number of reports suggest the role of HA in female reproduction and interest in its application in assisted reproduction is rising. However, there are contrasting data about the effectiveness of adding HA to the embryo-transfer medium on improving pregnancy rates (Oats, et al ${ }^{[5]}$ ). Several studies evaluated the co-administration of Letrozole during ovarian stimulation in patients suffering from a diminished ovarian reserve, yielding conflicting results. In these studies, Letrozole was started either concomitantly with or before gonadotropins, and was given for a total of 5 stimulation days (Elsedeek, et al ${ }^{[6]}$, Ahmied, M. $\left.{ }^{[7]}\right)$. Hypothetically, extending the duration of letrozole co-treatment may provide a more pronounced effect on intrafollicular androgens and circulating estrogen levels. Letrozole co-treatment during the entire stimulation course improves ovarian response in normal responders undergoing IVF-ET (Hameed 
and Ahmeid ${ }^{[87}$ ). The study aims to evaluate the use of letrozole in the stimulation of infertile women in relation to hyaluronic acid levels in endometrium.

\section{Materials and Methods}

This comparative prospective study was conducted in the High Institute of Infertility Diagnosis and Assisted Reproductive Technologies, Al Nahrain University, from September 2019 to March 2020. The study included a total of 40 women who attended the infertility clinic of the High Institute of Infertility Diagnosis and Assisted Reproductive Technologies, Al-Nahrain University from September 2019 to March 2020. All couples subjected to full history taking, complete general examination, complete gynecological examination, and infertility workup including husband's seminal fluid analysis, basal hormonal analysis, and uterine cavity assessment by ultrasound and tubal patency evaluation by hysterosalpingogram. The females were classified into 2 groups each consists of 20 females. The control group did not receive any ovarian stimulation drugs (natural cycle). In the $2^{\text {nd }}$ group (studied group) ovulation induction programs were used, 20 were stimulated by letrozole $2.5 \mathrm{mg}$ tablets from cycle $3^{\text {rd }}$ day for 5 days two times daily in addition to gonadotropin ampule r-FSH $75 \mathrm{IU}$ from day 4 of the cycle with dose adjusted according to patient's response. The ovarian stimulation protocol was chosen for each patient according to her age, history of previous cycle response, and hormonal assay. Evaluation of thickness and pattern of the endometrium, size, and the number of mature follicles was performed by transvaginal ultrasonography on the $2^{\text {nd }}$ day of the menstrual cycle and cycle day 11-14 before HCG injection (ovulatory phase). Endometrial wash was done on trigger day (day 11-14) for assessment of hyaluronic acid concentration. Pregnancy outcome was used as a main comparative parameter between selected groups and the study included aspiration of endometrial fluid for determination of hyaluronic acid 


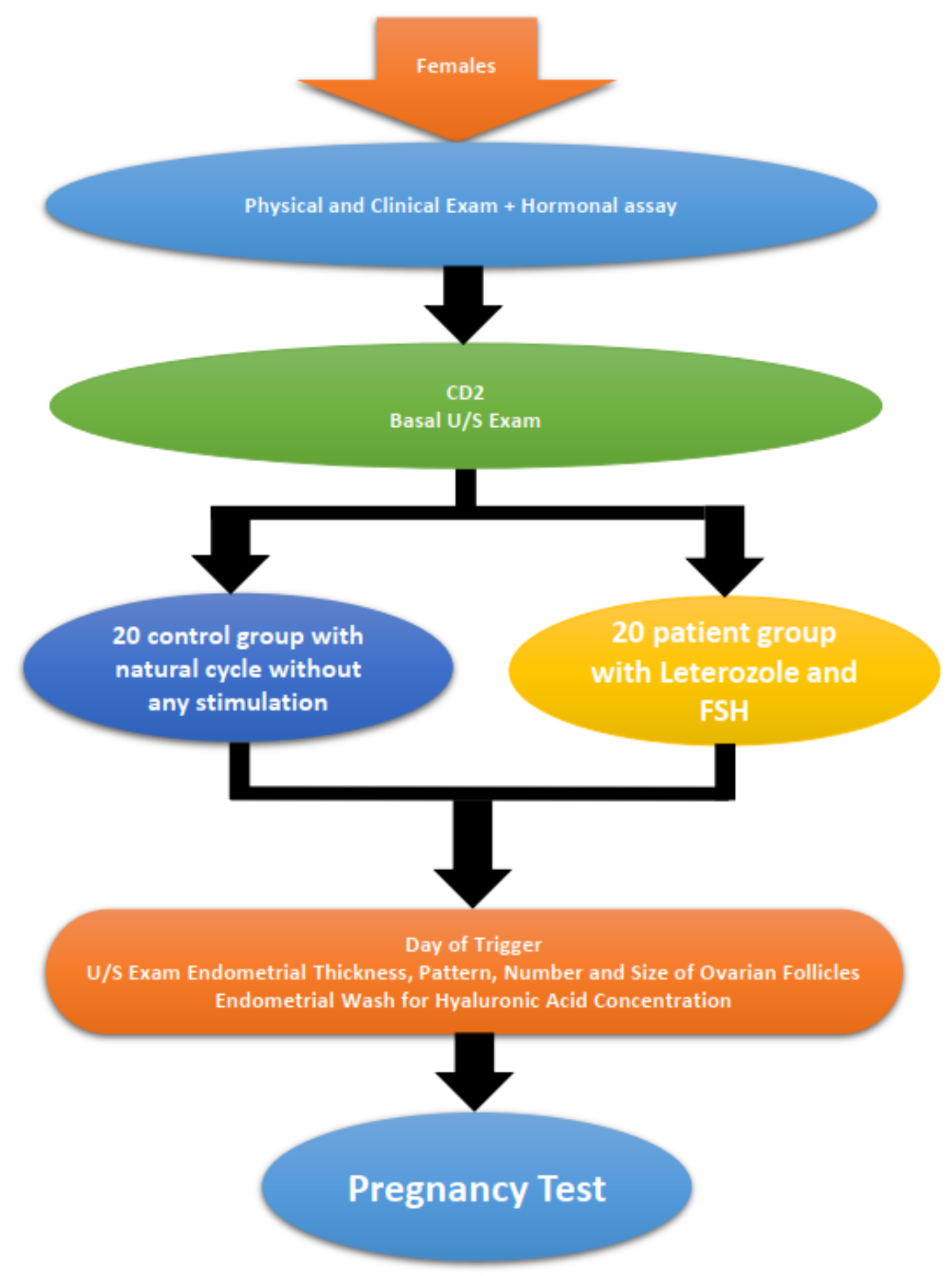

Figure (1): Methodology of the study 
level by ELISA technique. The methodology is shown in Figure 1.

\section{Aspiration of endometrial fluid}

The present study included aspiration of endometrial wash fluid on the day of trigger by putting the patient in the lithotomy position. Cleaning of the vagina was done by normal saline wash. Using a sterile IUI catheter connected to a disposable syringe; three $\mathrm{ml}$ of sterile normal saline was injected slowly into the endometrial cavity after passing the cervical mucus and re-aspirated after thirty seconds. This volume was chosen after making a pilot study since a larger amount might spill into the ovarian tubes and may go farther into the peritoneal cavity causing peritoneal irritation, a lesser amount might not cover the entire cavity and the samples will not be sufficient for measuring the hyaluronic acid concentration. Samples were transferred into a plain sterile tube for assessment of HA concentration (González-Ramos, et al $\left.{ }^{[9]}\right)$.

\section{Results}

In this study, the majority of women enrolled have belonged to rural area (60\%) and below 30 years old (55\%), parity was 0-5 but the majority were complaining of primary infertility $(60 \%)$ and the infertility duration from 2 years to $>7$ years, and with body mass index $26.14 \pm 4.31 \mathrm{~kg} / \mathrm{m}^{2}$ (Mean $\left.\pm \mathrm{SD}\right)$ as shown in Table 1. The study showed that mean of hyaluronic acid was elevated significantly in women who received letrozole plus Gonadotropin $(158.7 \pm 19.7 \mathrm{pg} / \mathrm{ml})$ than the control group $(146.1 \pm 26.2 \mathrm{pg} / \mathrm{ml})$ as shown in Table 2. The study showed no correlation between hyaluronic acid and $\mathrm{LH}$ at the day of triggering of ovulation in women who received letrozole plus Gonadotropin (r: 0.03 and $\mathrm{P}>0.05$ ), as shown in Figure 2. The study showed a positive correlation of hyaluronic acid with $E_{2}$ at the day of triggering of ovulation in women who received letrozole plus Gonadotropin, (r: 0.28 and $\mathrm{P}=0.22)$, (Figure 3). The study showed a positive correlation between 
Table (1): General characteristics of females enrolled in the present study

\begin{tabular}{|c|c|c|}
\hline Characteristics & $\begin{array}{c}\text { Number of cases } \\
\text { (Total: 20) }\end{array}$ & $\begin{array}{c}\text { Percentage } \\
(\%)\end{array}$ \\
\hline \multicolumn{3}{|c|}{ Residence } \\
\hline Rural & 12 & $60 \%$ \\
\hline Urban & 8 & $40 \%$ \\
\hline \multicolumn{3}{|c|}{ Age groups (years) } \\
\hline$<\mathbf{3 0}$ & 11 & $55 \%$ \\
\hline$\geq \mathbf{3 0}$ & 9 & $45 \%$ \\
\hline Mean \pm SD & $29.5 \pm 4.52$ & \\
\hline \multicolumn{3}{|c|}{ Parity } \\
\hline $\mathbf{0}$ & 10 & $50 \%$ \\
\hline 1 & 5 & $25 \%$ \\
\hline $2-3$ & 4 & 20 \\
\hline $4-5$ & 1 & $5 \%$ \\
\hline \multicolumn{3}{|c|}{ Duration of infertility (years) } \\
\hline $2-4$ & 12 & $60 \%$ \\
\hline $5-7$ & 6 & $30 \%$ \\
\hline$>7$ & 2 & $10 \%$ \\
\hline $\begin{array}{c}\text { BMI }\left(\mathbf{k g} / \mathbf{m}^{2}\right) \\
(\text { Mean } \pm \text { SD) }\end{array}$ & $26.14 \pm 4.31$ & \\
\hline LH (mlU/ml) & $8.67 \pm 4.54$ & \\
\hline E2 (pg/ml) & $280.5 \pm 191.4$ & \\
\hline $\begin{array}{c}\text { progesterone } \\
(\mathrm{ng} / \mathrm{ml})\end{array}$ & $4.15 \pm 3.2$ & \\
\hline
\end{tabular}

Table (2): Level of hyaluronic acid in the studied groups

\begin{tabular}{|c|c|c|c|}
\hline $\begin{array}{c}\text { Hyaluronic } \\
\text { acid }(\mathrm{pg} / \mathrm{ml})\end{array}$ & Treated Group & Control Group & \multirow{2}{*}{ P-Value } \\
\cline { 1 - 3 } $\mathrm{N}$ & 20 & 20 & \\
\hline (Mean \pm SD) & $158.7 \pm 19.7$ & $146.1 \pm 26.2$ & 0.031 \\
\hline
\end{tabular}




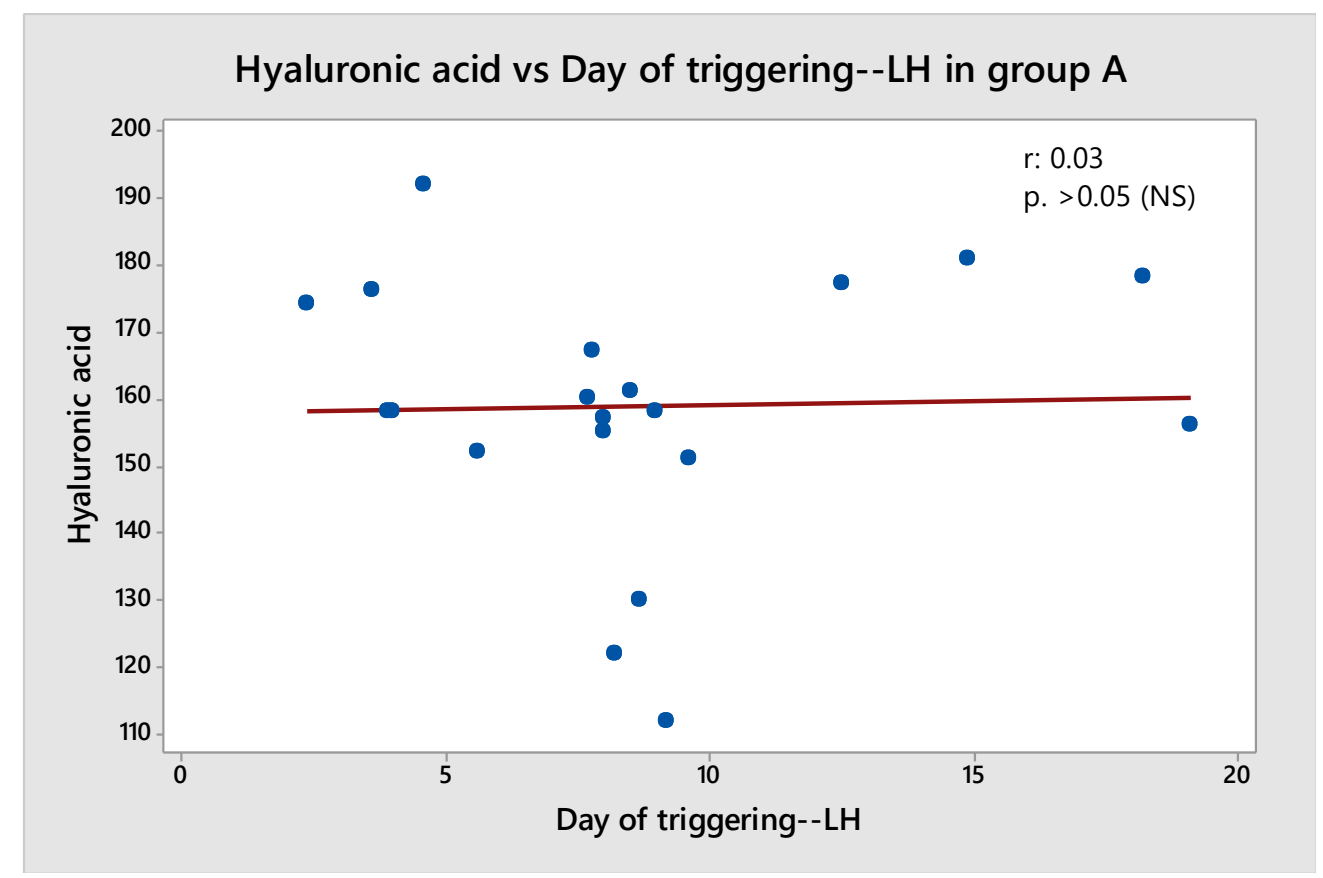

Figure (2): Correlation between hyaluronic acid and LH of group A at day of follicles triggering

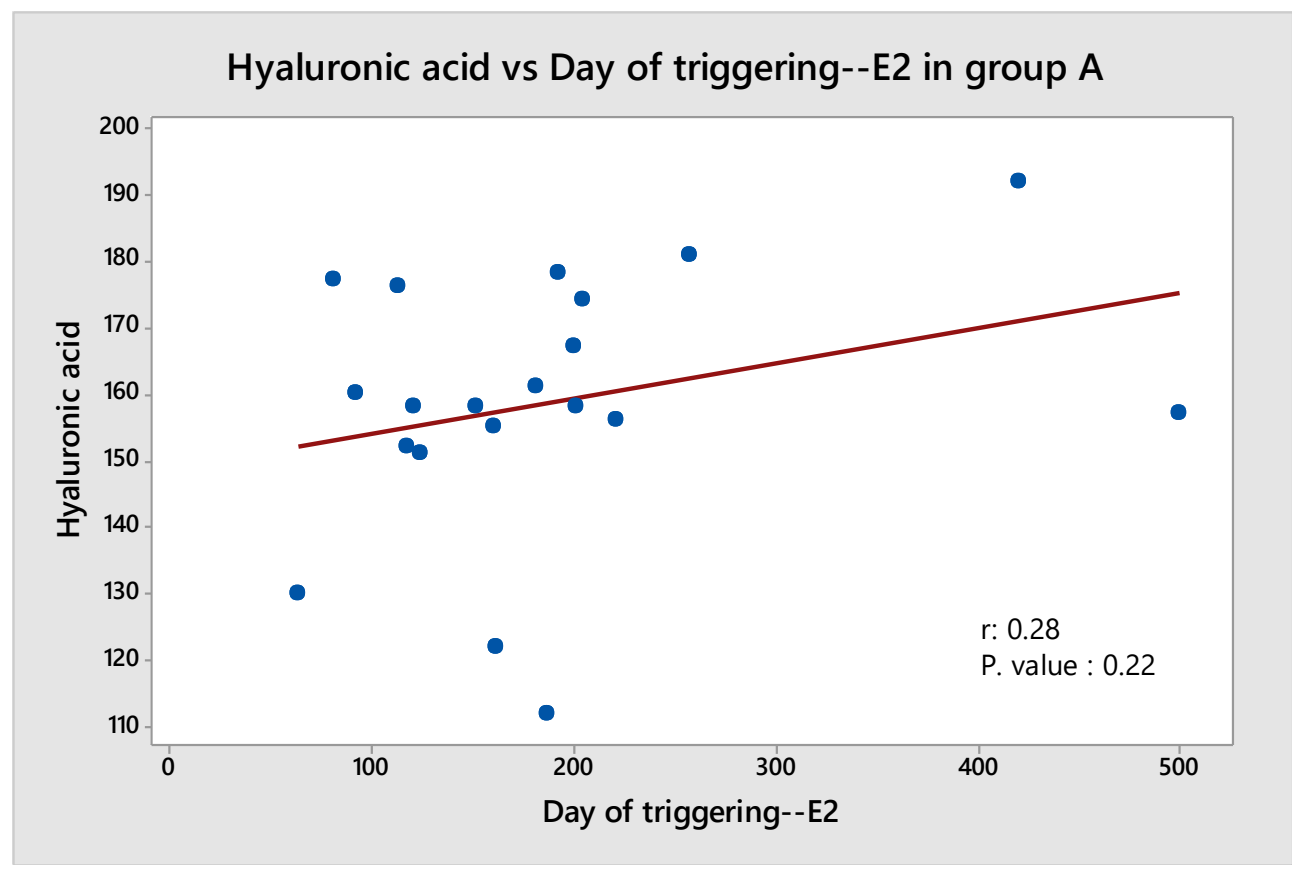

Figure (3): Correlation between hyaluronic acid and $\mathrm{E}_{2}$ of group $\mathrm{A}$ at day of follicles triggering 


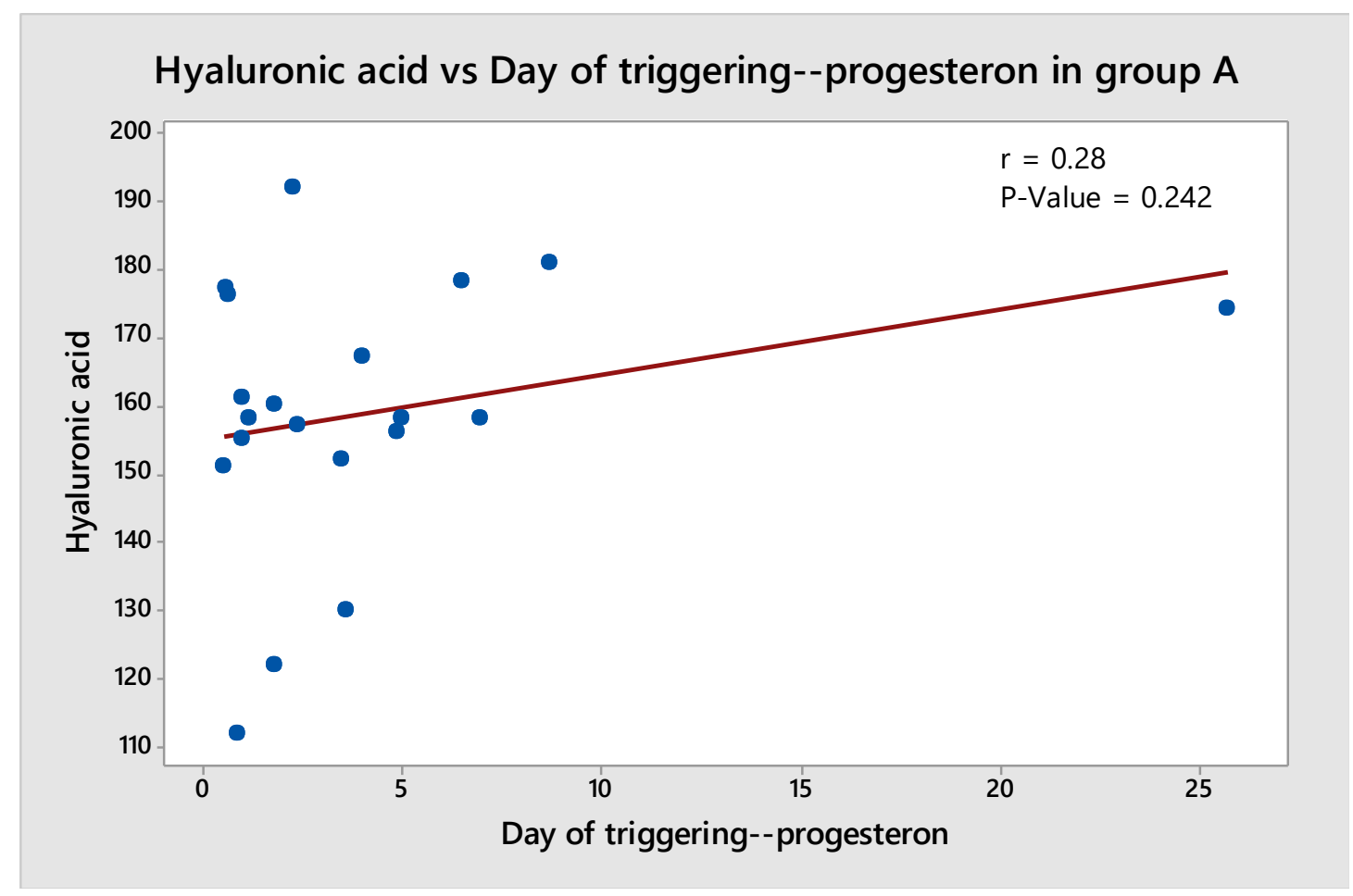

Figure (4): Correlation between hyaluronic acid and progesterone of group A at day of follicles triggering

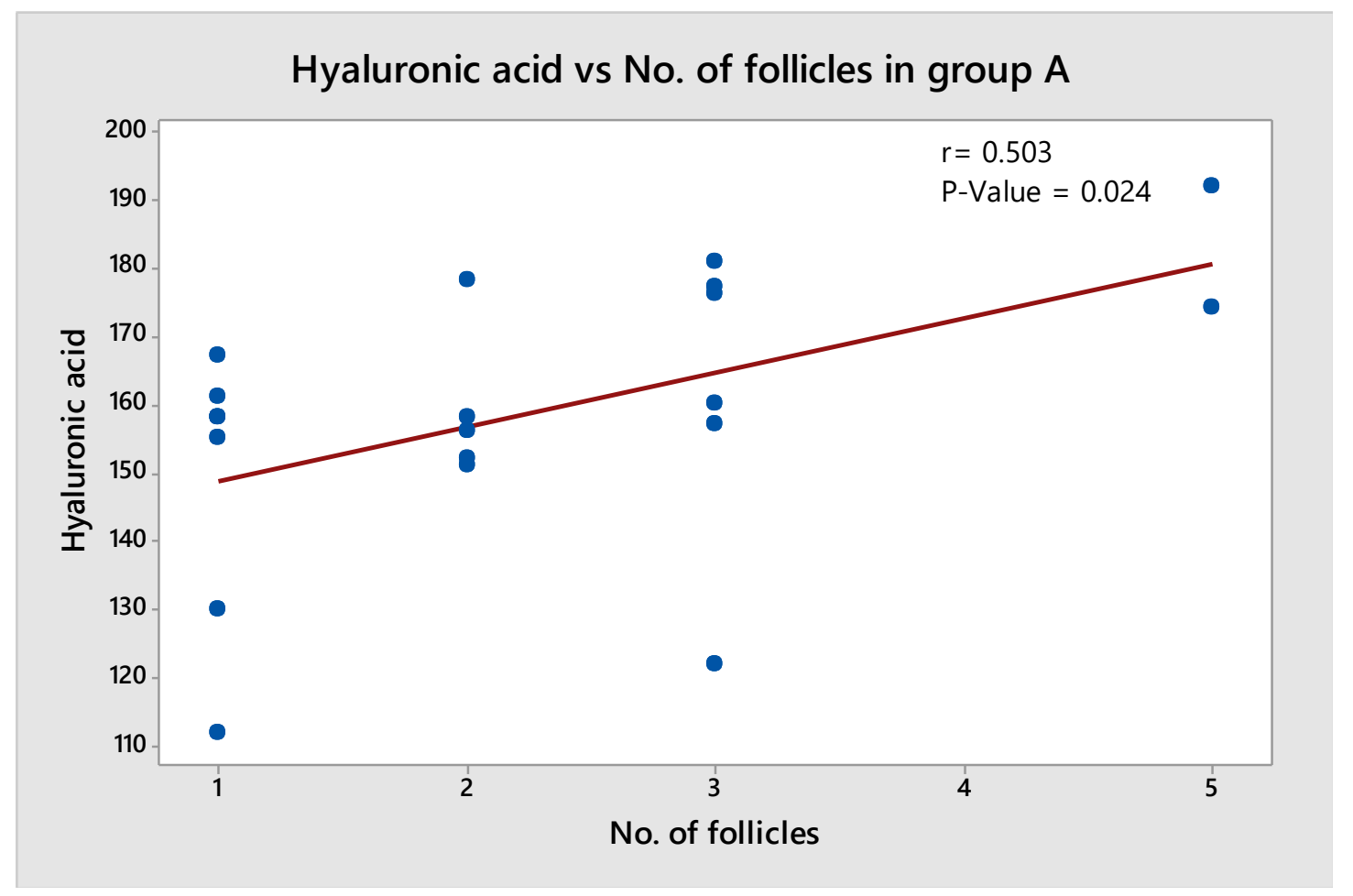

Figure (5): Correlation between hyaluronic acid number of follicles in group A 


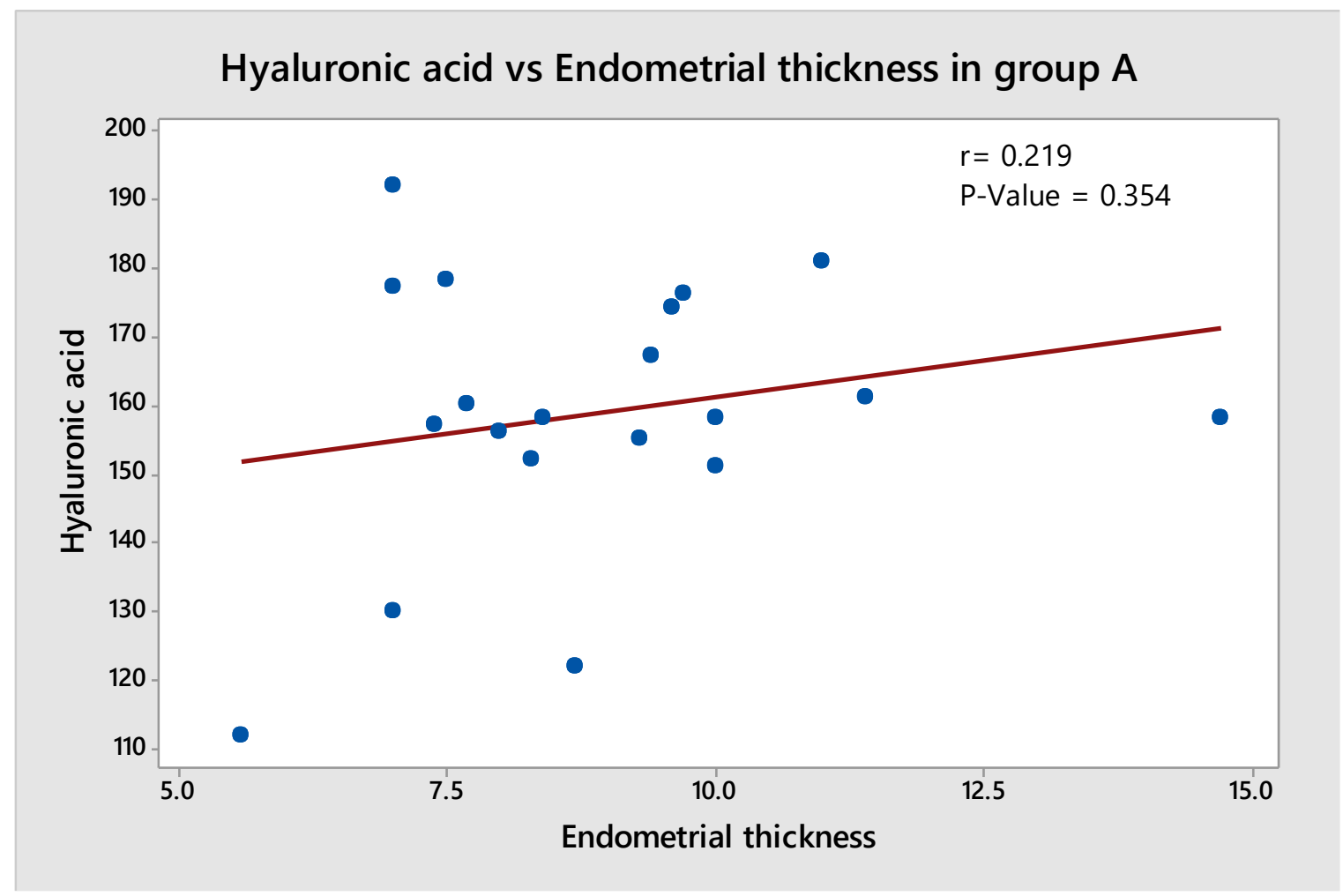

Figure (6): Correlation between hyaluronic acid and endometrial thickness in group A

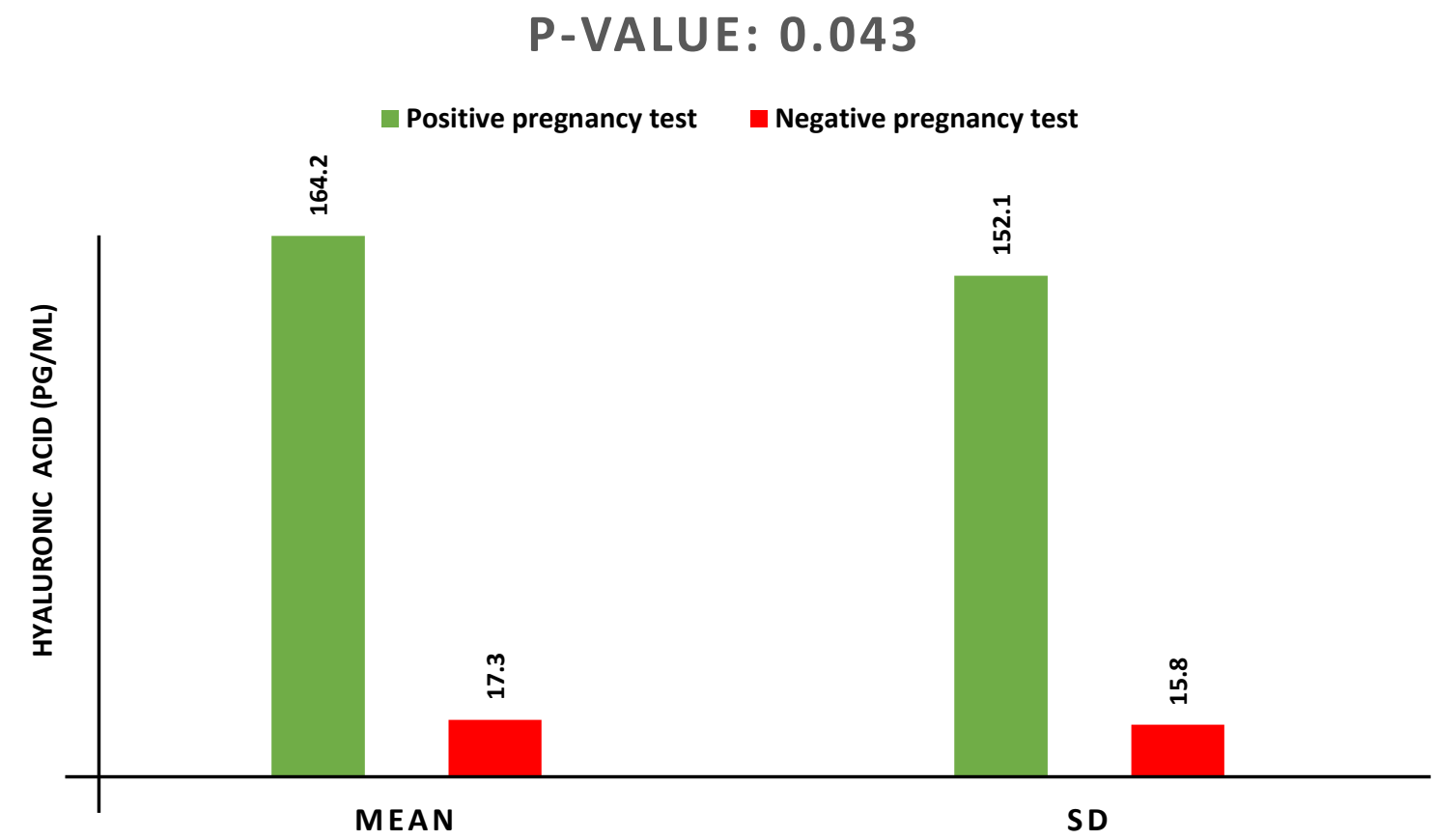

Figure (7): Relation of HA with stimulation outcomes 
hyaluronic acid and progesterone at the day of triggering of ovulation in women received letrozole plus Gonadotropin, $(\mathrm{r}=0.28$ and $\mathrm{P}=0.24)$, (Figure 4). The study showed a positive correlation between hyaluronic acid and the number of follicles in women after receiving letrozole plus Gonadotropin, ( $\mathrm{r}=0.503$ and $\mathrm{P}=0.024)$, (Figure 5). The study showed a positive correlation between hyaluronic acid and endometrial thickness in women who received letrozole plus Gonadotropin, $(\mathrm{r}=0.219$ and $\mathrm{P}=0.354)$, (Figure 6). The study revealed that HA mean was elevated significantly $(\mathrm{P}<0.05)$ in women who became pregnant after stimulation protocol compared with women who failed to be pregnant (164.2 vs. $152.1 \mathrm{pg} / \mathrm{ml}$ ) as shown in Figure 7.

\section{Discussion}

It is important to understand the host physiological and pathological mechanisms underlying events of the female reproductive tract, such as endometriosis, tumors, and infertility
(González-Ramos, et al ${ }^{[9]}$ ). There were very few declared studies regarding the relation of hyaluronic acid with infertility and no previous studies were done about the levels of HA in women who received letrozole plus Gonadotropin and who received Clomid plus Gonadotropin. A study done by (Simões, et al ${ }^{[10]}$ ) indicated that there was an elevated concentration of hyaluronic acid in women endometrium in the proliferative phase and higher HAS1 and HAS2 reactivity when compared with normal women. In addition, (Nagyova, $E$ ${ }^{[11]}$ ) indicated that HA levels were increased in the endometrial stroma during the secretory phase of the menstrual cycle and fall to very low levels at menstruation, suggestive of a role in implantation. In different studies, (Gomes, et al ${ }^{[12]}$ ) in the study the immuneexpression of hyaluronic acid (HA) in the uterine horns of the mouse throughout the estrous cycle phases, their data showed that the highest concentration of HA in uterine horns occurred during diestrus compared with other phases. Moreover, 
(Mohey-Elsaeed, et al ${ }^{[13]}$ ) reported spatiotemporal expression of RHAMM protein in mouse endometrium during the estrous cycle and peri-implantation period, suggesting its possible role in endometrial receptivity. HA has also been shown to improve the cryotolerance of blastocysts, which then leads to increased birth rates in cows (Lane, et al ${ }^{[14]}$ ). Moreover, HA was detected in oviductal fluids collected by catheterization during the estrous cycle in heifers and cows (Simon, et al ${ }^{[15]}$ ) and was shown to be highest at ovulation (Stojkovic, et al ${ }^{[16]}$ ). Synthesis of HA is increased significantly in the uterus of mice on the day of implantation (Fouladi-Nashta, et al ${ }^{[17]}$ ), and HA differential expression in the human endometrium during the menstrual cycle implies its involvement in implantation. In the human uterus, the peak expression of HAS and CD44 is in the mid-secretory stage (Afify, et al ${ }^{[18]}$ ). There is a plethora of data suggesting the beneficial roles for HA in human embryo implantation (Ahmeid M. ${ }^{[7]}$, GonzálezRamos, et al $\left.{ }^{[9]}\right)$.

\section{Conclusions}

It was concluded that hyaluronic acid was elevated significantly in women who received ovulation stimulation drugs and letrozole was a good treatment for anovulatory cycle women.

\section{Acknowledgment}

We would like to acknowledge Al Nahrain University, Baghdad, Iraq.

\section{Funding}

This work received no funding.

\section{Author Contribution}

\begin{abstract}
AlJuboory, SKH performed the study, examined and reviewed results, and manuscript writing with the help and supervision of Jwad, MA, and Al-Hilli, N.

\section{Conflict of Interest}

The authors declare no conflict of interest.
\end{abstract}




\section{Ethical Clearance}

The study was approved by the

Ethical Approval Committee.

\section{References}

[1]Bergqvist AS, Yokoo M, Heldin P. Hyaluronan and its binding proteins in the epithelium and intraluminal fluid of the bovine oviduct. Zygote, 2005; 13(3): 207-218. [Online Article Link]

[2] Campbell S. Ultrasound Evaluation in Female Infertility: Part 1, the Ovary and the Follicle. Obstetrics and Gynecology Clinics. 2019; 46(4): 683696. [Online Article Link]

[3] Chun S, Seo J, Rim Y. Efficacy of hyaluronan-rich transfer medium on implantation and pregnancy rates in fresh and frozen-thawed blastocyst transfers in Korean women with previous implantation failure. Obstetrics \& gynecology science. 2016; 59(3): 201-207. [Online Article Link]

[4] Al-Hussaini TK, Shaaban OM. Aspiration of endometrial cavity fluid at the time of egg collection. Middle East Fertility Society Journal. 2018 Dec 1;23(4):354-6. [Online Article Link]

[5] Oats JJ, Abraham S. Llewellyn-Jones Fundamentals of Obstetrics and Gynaecology E-Book. Elsevier Health
Sciences; 2015 Nov 13. [Online Article Link]

[6] Elsedeek M, Elmaghraby $\mathrm{H}$. Predictors and characteristics of letrozole induced ovulation in comparison with clomiphene induced ovulation in anovulatory PCOS women. Middle East Fertility Society Journal. 2011; 6(2): 125-130. [Online Article Link]

[7] Ahmeid M. Correlation between follicular fluid leptin and the pregnancy rate in women who underwent ICSI. Tikrit Med J. 2017; 22: 248-53. [Online Article Link]

[8] Hameed B, Ahmeid M. Serum follistatin and its role in intracytoplasmic sperm injection outcomes. Medical Journal of Babylon. 2019; 16(4): 302-306. [Online Article Link]

[9] González-Ramos R, Van Langendonckt A, Defrère $S$, Lousse JC, Colette S, Devoto L, Donnez J. Involvement of the nuclear factor $-\kappa \mathrm{B}$ pathway in the pathogenesis of endometriosis. Fertility and sterility. 2010 Nov 1;94(6):1985-94. [Online Article Link]

[10] Simões SR, Carbonel AA, Borges FT, Baracat MC, da Silva Sasso GR, Simões MJ, Serafini PC, Soares JM, Nader HB, Baracat EC. Analysis of hyaluronic acid in the endometrium of women with polycystic ovary syndrome. Gynecological 
Endocrinology. 2019 Feb 1;35(2):133-

7. [Online Article Link]

[11] Nagyova E. The biological role of hyaluronan-rich oocyte-cumulus extracellular matrix in female reproduction. International Journal of Molecular $\quad$ Sciences. 2018 Jan;19(1):283. [Online Article Link]

[12] Gomes RC, Verna C, Nader HB, dos Santos Simões R, Dreyfuss JL, Martins JR, Baracat EC, de Jesus Simões M, Soares Jr JM. Concentration and distribution of hyaluronic acid in mouse uterus throughout the estrous cycle. Fertility and sterility. 2009 Aug 1;92(2):78592. [Online Article Link]

[13] Mohey-Elsaeed O, Marei WF, Fouladi-Nashta AA, El-Saba AA. Histochemical structure and immunolocalisation of the hyaluronan system in the dromedary oviduct. Reproduction, Fertility and Development. 2016 Jun 8;28(7):93647. [Online Article Link]

[14] Lane M, Maybach JM, Hooper K, Hasler JF, Gardner DK. Cryo-survival and development of bovine blastocysts are enhanced by culture with recombinant albumin and hyaluronan. Molecular Reproduction and Development: Incorporating Gamete Research. 2003 Jan;64(1):70-78. [Online Article Link]

[15] Simon A, Safran A, Revel A, Aizenman E, Reubinoff B, Porat-Katz
A, Lewin A, Laufer N. Hyaluronic acid can successfully replace albumin as the sole macromolecule in a human embryo transfer medium. Fertility and sterility. 2003 Jun 1;79(6):1434-8. [Online Article Link]

[16] Stojkovic M, Krebs O, Kölle S, Prelle K, Assmann V, Zakhartchenko V, Sinowatz F, Wolf E. Developmental regulation of hyaluronan-binding protein (RHAMM/IHABP) expression in early bovine embryos. Biology of reproduction. 2003 Jan 1;68(1):60-66. [Online Article Link]

[17] Fouladi-Nashta AA, Raheem KA, Marei WF, Ghafari F, Hartshorne G. Regulation and roles of the hyaluronan system in mammalian reproduction. Reproduction. 2017 Feb 1;153(2): R43-R58. [Online Article Link]

[18] Afify AM, Craig S, Paulino AF. Temporal variation in the distribution of hyaluronic acid, CD44s, and CD44v6 in the human endometrium across the menstrual cycle. Applied Immunohistochemistry \& Molecular Morphology. 2006 Sep 1;14(3):32833. [Online Article Link] 


\section{Authors Biographies}

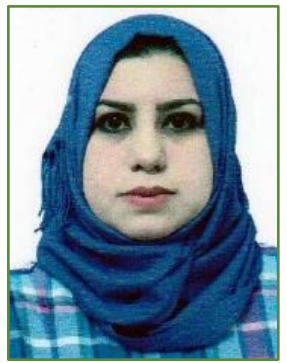

Dr. Sarab Khalaf Hammood

AlJuboory

She received the M.B.CH.B. from

the College of medicine, University of Baghdad in 2002. She worked in Mesan and Kirkuk until she occupied a position of senior house officer during her permanency in obstetrics and gynecology 2008-2010 and from 2010-2012 she was the manager of a primary healthcare center until the start of residency program in 2012 at Tikrit Teaching Hospital and graduated as a specialist in Obstetrics and Gynecology in 2014 with H.D of Obst. And Gyne. She worked as a specialist in Kirkuk General Hospital in Kirkuk city. Currently, she is attending in Al-Nahrain University, the High Institute of Infertility Diagnosis and Assisted Reproductive Technologies.

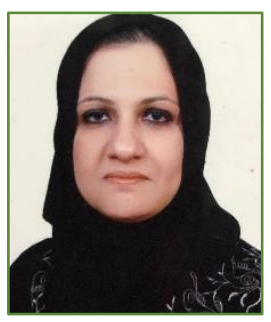

\section{Dr. Mufeda Ali Jwad}

She received her $\mathrm{MBChB}$. From the College of Medicine at the University of Baghdad in 1996. Her M.Sc. in Applied Embryology and her Ph.D. in Infertility and Clinical Reproduction were from the High Institute of Infertility Diagnosis and Assisted Reproductive Technologies, Al Nahrain University in 2007 and 2018 respectively. She worked as a rotator in the Baghdad health department from 1996-1999. She worked in Gyn. \& Obs. in Alsamawa general hospital and Babylon hospital from 20002003. She worked at the Babylon University, College of Medicine, anatomy and embryology department from 2003-2004. She has been working as a specialist physician and a consultant clinic at the High Institute of Infertility Diagnosis and Assisted Reproductive Technologies, Al Nahrain University from 2008-2015. Currently, she is an assistant professor and specialist in infertility and clinical reproduction. She is the head of the clinical reproductive physiology department from 2019 till now. She has more than 25 published articles in national and international journals.

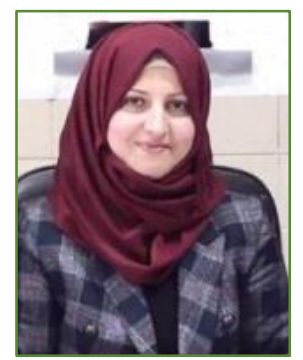

\section{Dr. Nadia Mudher}

\section{Sulaiman Al-Hilli}

She was born in Babylon, Iraq in 1976. She received the M.B.Ch.B. from College of Medicine, the University of Babylon in 1999, the Diploma in Obstetrics \& Gynecology in 2005, Iraqi Board in Obstetrics \& Gynecology (FIBMS) in 2006, the Part I MRCOG in 2006, and the Certificate of minimal access surgery from the Iraqi Ministry of Health in 2017. Currently, she is an Assistant Professor and the Head of the department in Obstetrics \& Gynecology department, College of Medicine, University of Babylon. She is also a lecturer and supervisor of Ph.D. students in the High Institute of Infertility and Assisted Reproductive Technologies since 2016. She is a member of the medical education committee at the University of Babylon, College of Medicine, and a member of the scientific committee of Obs. \& Gyne. department at the University of Babylon, College of Medicine. She participated in more than, 25 Symposiums, 3 International Symposiums, 18 
National Conferences, 15 International Conferences, 16 Workshops, and 9 Training Courses. She published more than 21 articles both local and international. She has more than 200 diagnostic \& operative hysteroscopy operations \& More than 200 diagnostic and operative laparoscopies performed for infertility patients.

\section{How to cite:}

AlJuboory SKH; Jwad MA; Al-Hilli N. Effect of Letrozole on Hyaluronic Acid Concentration of the Endometrial Wash; Iraqi Journal of Embryos and Infertility Researches (IJEIR), (2020); 10(1): 20-34. Doi: http://doi.org/10.28969/IJEIR.v10.i1.r2

\section{(c) (i) 2020 Author(s)}

This article is licensed under a Creative Commons Attribution 4.0 International License, which permits use, sharing, adaptation, distribution and reproduction in any medium or format, as long as you give appropriate credit to the original author(s) and the source, provide a link to the Creative Commons license, and indicate if changes were made. http://creativecommons.org/licenses/by/4.0/. 